\title{
A three-dimensional collagen scaffold cell culture system for screening anti-glioma therapeutics
}

\author{
Donglai Lv ${ }^{1,2}$, Shi-cang $\mathbf{Y u}^{1,2}$, Yi-fang Ping ${ }^{1,2}$, Haibo $\mathbf{W u}^{1,2}$, Xilong Zhao ${ }^{1,2}$, Huarong \\ Zhang $^{1,2}$, Youhong Cui ${ }^{1,2}$, Bing Chen ${ }^{3,4}$, Xia Zhang ${ }^{1,2}$, Jianwu Dai ${ }^{3,4}$, Xiu-wu Bian ${ }^{1,2, *}$, \\ Xiao-hong Yao ${ }^{1,2, *}$ \\ ${ }^{1}$ Institute of Pathology and Southwest Cancer Center, Southwest Hospital, Third Military Medical University, Chongqing, China \\ ${ }^{2}$ Key Laboratory of Tumor Immunopathology, Ministry of Education of China, Chongqing, China \\ ${ }^{3}$ State Key Laboratory of Trauma, Burns and Combined Injury, Institute of Combined Injury, School of Military Preventive \\ Medicine, Third Military Medical University, Chongqing, China \\ ${ }^{4}$ Institute of Genetics and Development, Chinese Academy of Sciences, Beijing, China \\ *These authors have contributed equally to this work \\ Correspondence to: Xiao-hong Yao, email: yxh15@hotmail.com \\ Xiu-wu Bian, email: bianxiuwu@263.net \\ Keywords: chemosensitivity, collagen scaffold, glioma stem cells, three-dimensional culture, MGMT \\ Received: February 27, $2016 \quad$ Accepted: June 30, $2016 \quad$ Published: July 28, 2016
}

\section{ABSTRACT}

Three-dimensional (3D) culture, which can simulate in vivo microenvironments, has been increasingly used to study tumor cell biology. Since most preclinical antiglioma drug tests still rely on conventional 2D cell culture, we established a collagen scaffold for 3D glioma cell culture. Glioma cells cultured on these 3D scaffolds showed greater degree of dedifferentiation and quiescence than cells in 2D culture. 3D-cultured cells also exhibited enhanced resistance to chemotherapeutic alkylating agents, with a much higher proportion of glioma stem cells and upregulation of 06-methylguanine DNA methyltransferase (MGMT). Importantly, tumor cells in 3D culture showed chemotherapy resistance patterns similar to those observed in glioma patients. Our results suggest that 3D collagen scaffolds are promising in vitro research platforms for screening new anti-glioma therapeutics.

\section{INTRODUCTION}

Malignant glioma is the most common and deadly type of brain tumor [1]. In the past decade, even with improvements in surgical, radiation and chemotherapeutic methods to treat glioblastoma multiform (GBM), the most malignant glioma (World Health Organization [WHO] grade IV), the median patient survival has only increased from 10 months to 14 months [2]. New, more effective treatment regimens are urgently needed. Most drugs failed to achieve satisfactory effects in a number of recent multicenter anti-glioma Phase II clinical trials. It has been shown that traditional two-dimensional (2D) cell culture systems perform poorly as preclinical drug discovery tools, and are not suitable models for investigating solid tumors [3-5]. Current 2D cell culture systems provide neither good glioma stem cell (GSC) enrichment nor biomimetic microenvironments, including appropriate architecture, extracellular matrix (ECM) components and cell interactions [6]. This leads to large deviations in drug sensitivities between in vitro tests and in vivo clinical evaluations [3]. Therefore, building new in vitro anti-glioma drug research models will be crucial for the development of effective anti-glioma therapeutics [7].

To address these challenges, several 3D tumor cell culture techniques have been reported [8-11]. Cancer cells cultured in 3D structures may be superior for use in in vitro trials due in part to increased cell-cell and cellECM interaction. 3D scaffolds may better simulate native tumor microenvironment ECM [12] and provide more accurate drug efficacy analyses [13]. The principal ECM component identified in the normal brain is hyaluronan (HA) [14], therefore brain tissue engineering studies, including those for malignant tumors [15], frequently choose HA as a matrix-mimetic platform. However, glioma ECM composition is critically different from that 
of normal brain. Glioma tissues contain large amounts of fibrillary collagens [16], which are important ligands for activation of signal transduction networks required for glioma malignancy [17]. In this study, we proposed that collagen is a superior biomaterial for in vitro glioma studies. We developed a porous collagen scaffold and constructed a 3D glioma culture model using this scaffold.

To evaluate anti-glioma drug efficacies and to clarify different drug-resistance mechanisms, we performed in vitro trials using our 3D collagen scaffolds. Morphology, proliferation, growth kinetics, and chemosensitivity of glioma cells in 3D collagen scaffolds were remarkably different from their 2D monolayer counterparts. Relatively slow cell growth in the 3D model was attributed to decreased proliferation and increased quiescence. Dedifferentiation and increased drug resistance were also observed in 3D-cultured glioma cells. Drug resistance was attributed to MGMT upregulation and enhanced glioma cell stemness.

\section{RESULTS}

\section{Morphology and structure of glioma cells in 3D culture}

We observed changes in cell morphology in 3D collagen scaffold cultures as compared to 2D cultures. After seven days in culture, U87 and primary glioma cells were fixed, dehydrated and embedded in paraffin for H\&E staining or dried for SEM imaging. Glioma cells in 3D collagen scaffolds (Figure 1B) but not in 2D culture plates (Figure 1A) displayed a high degree of similarity with primary tumor tissue. SEM showed that U87 cells in 2D culture were fusiform, flat and epithelioid (Figure 1C). Glioma cells in 3D scaffolds grew as small, round or ovoid cells appeared stereoscopic and formed a multi-layer structure (Figure 1D). Primary tumor cells cultured in 3D collagen scaffolds (Figure 1E) were morphologically similar to glioma cells in human tumor tissues (Figure 1F), and grew in complex formations with cilia or microvilli on their surface. Furthermore, with increased culture duration (3 to 10 days), cells constituted 3D structures throughout the deep scaffold (Supplementary Figure S1A-S1D). These results suggest that $3 \mathrm{D}$ collagen scaffolds more effectively mimic the in vivo microenvironment than $2 \mathrm{D}$ cultures.

\section{Growth profile of glioma cells in 3D culture}

We compared proliferation and cell cycle stage in glioma cells cultured in 3D collagen scaffolds with cells in 2D monolayer cultures. CCK 8 assay results showed that U87 cells grew more slowly in 3D scaffolds than in 2D monolayer cultures (Figure 2A). Statistically significant differences were observed after five days in culture. As compared to $2 \mathrm{D}$ culture, in $3 \mathrm{D}$ culture the proportion of cells in $\mathrm{G} 1 / \mathrm{G} 0$ phase increased from $58.05 \pm 7.76 \%$ to $69.37 \pm 4.20 \%$, and cells in $\mathrm{S}$ and $\mathrm{G} 2 / \mathrm{M}$ phases decreased from $28.51 \pm 3.85 \%$ to $17.45 \pm 3.02 \%$ and $13.44 \pm 3.96 \%$ to $13.18 \pm 1.82 \%$, respectively (Figure $2 \mathrm{~B}$ ). This suggests that cells grown in $3 \mathrm{D}$ scaffold culture accumulated in G0/G1 phase with concomitant reduction in $\mathrm{S}$ phase. We also used flow cytometry to determine whether 3D culture altered U87 cell proliferation, apoptosis and differentiation. The proportion of $\mathrm{Ki}-67^{+}$, caspase $-3^{+}$and cleaved PARP ${ }^{+}$U87 cells was $58.69 \%, 0.93 \%$ and $0.60 \%$, respectively, in $3 \mathrm{D}$ culture and $96.84 \%, 0.52 \%$ and $0.15 \%$, respectively, in 2D culture. On the other hand, the mean proportion of $\mathrm{GFAP}^{+} \mathrm{U} 87$ cells was $98.31 \pm 1.01 \%$ in $2 \mathrm{D}$ monolayers versus $86.03 \pm 3.64 \%$ in $3 \mathrm{D}$ scaffolds (Figure 2C). A similar effect was seen on primary glioma cells (Supplementary Figure S2). The results showed that 3D culture induced glioma cell dedifferentiation and decreased proliferation but did not impact apoptosis. As determined by flow cytometry, slower cell growth in 3D scaffolds could be attributed to both decreased proliferation and increased quiescence. Similar apoptosis rates between 2D and 3D cultures indicate that our collagen scaffolds exhibit good biocompatibility.

\section{Response to chemotherapeutic drugs}

DDP is the most commonly used cytotoxic chemotherapeutic agent, and CCNU and TMZ are the most common alkylating drugs clinical administered to glioma patients. U87 and primary glioma cells in 3D culture demonstrated greater resistance to all three drugs than cells in monolayer culture. Cells were more resistant to CCNU and TMZ than DDP. For U87 cells, the halfmaximal inhibitory concentrations $\left(\mathrm{IC}_{50}\right)$ in $3 \mathrm{D}$ and $2 \mathrm{D}$ cultures were: DDP: 34.39 and $11.94 \mu \mathrm{M}, \mathrm{CCNU}: 326.70$ and $7.78 \mu \mathrm{M}$, TMZ: 702.20 and $123.30 \mu \mathrm{M}$, respectively (Figure $3 \mathrm{~A}-3 \mathrm{C}$ ). For primary glioma cells, $\mathrm{IC}_{50} \mathrm{~s}$ in $3 \mathrm{D}$ vs. $2 \mathrm{D}$ cultures were: DDP: 10.63 and $3.73 \mu \mathrm{M}$; CCNU: 264.20 and $14.71 \mu \mathrm{M}$; TMZ: 1032.00 and $163.10 \mu \mathrm{M}$ (Figure 3D-3F). These data suggest that glioma cells in $3 \mathrm{D}$ culturing are more chemotherapeutic resistant as compared with cells in 2D culturing.

\section{Changes in the expression of chemotherapy resistance-related genes}

We investigated levels of multiple drug resistancerelated genes in U87 and primary glioma cells, including genes related to drug efflux (ABCB1, ABCC1, ABCC2, ABCC4, ABCG2, ATM), DNA damage repair (MGMT) and stemness (CD133). We found that both CD133 and MGMT were upregulated in U87 and primary glioma cells in 3D culture (Figure 4A-4D). Importantly, U87 is MGMT-negative in traditional 2D culture [18]. These results suggest that drug resistance in cells grown in 
3D collagen scaffolds could be attributed to increased DNA damage repair and stemness. The enhanced stemness phenotype agreed with the observed increases in the number of cells in G0/G1 phase and cellular dedifferentiation in $3 \mathrm{D}$ culture.
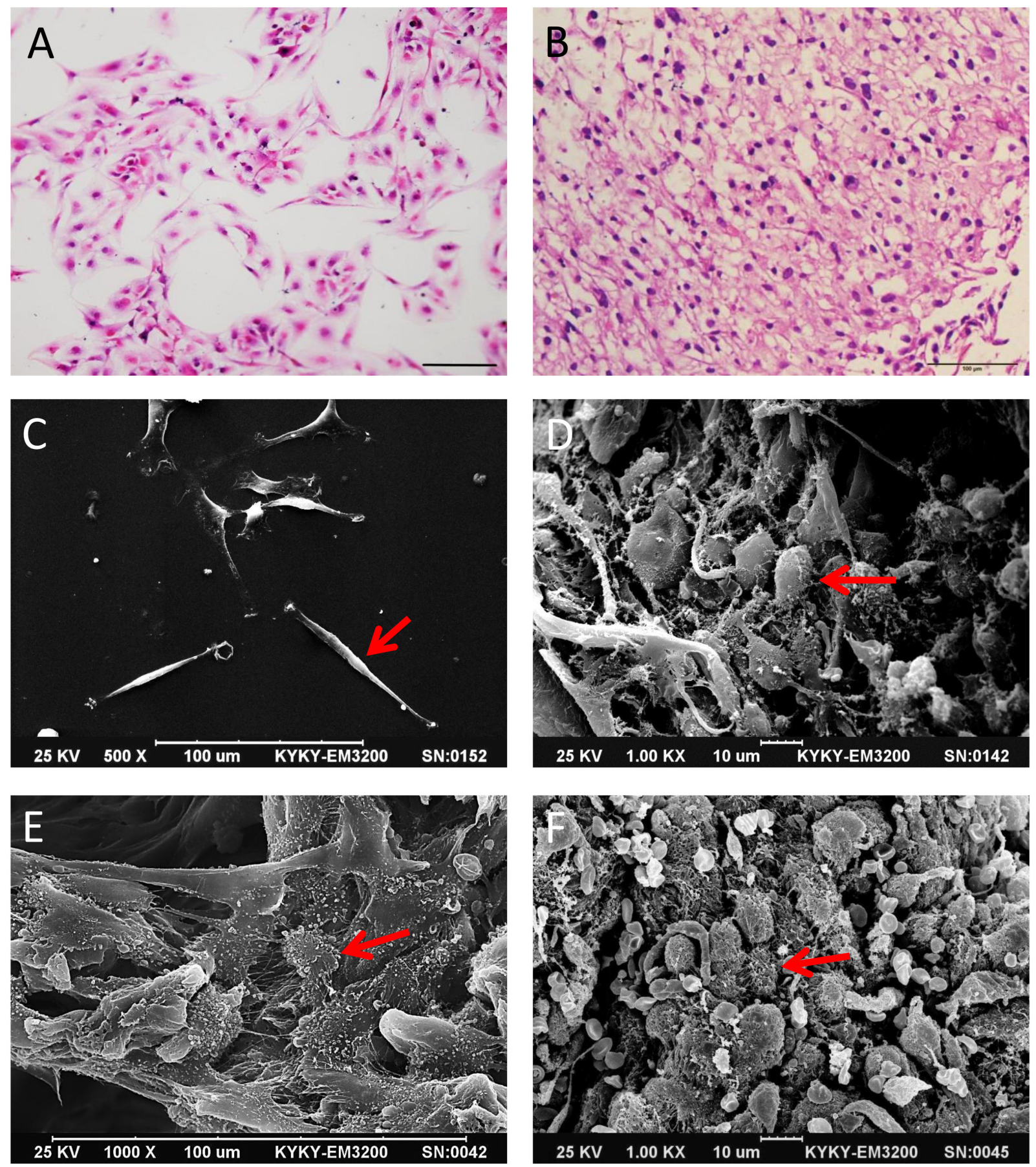

\section{Stemness in 3D-cultured glioma cells}

GSC-like properties were analyzed in U87 cells by immunofluorescent (IF) staining, FACS, qRT-PCR, Western blotting and colony/sphere-forming tests. CD133
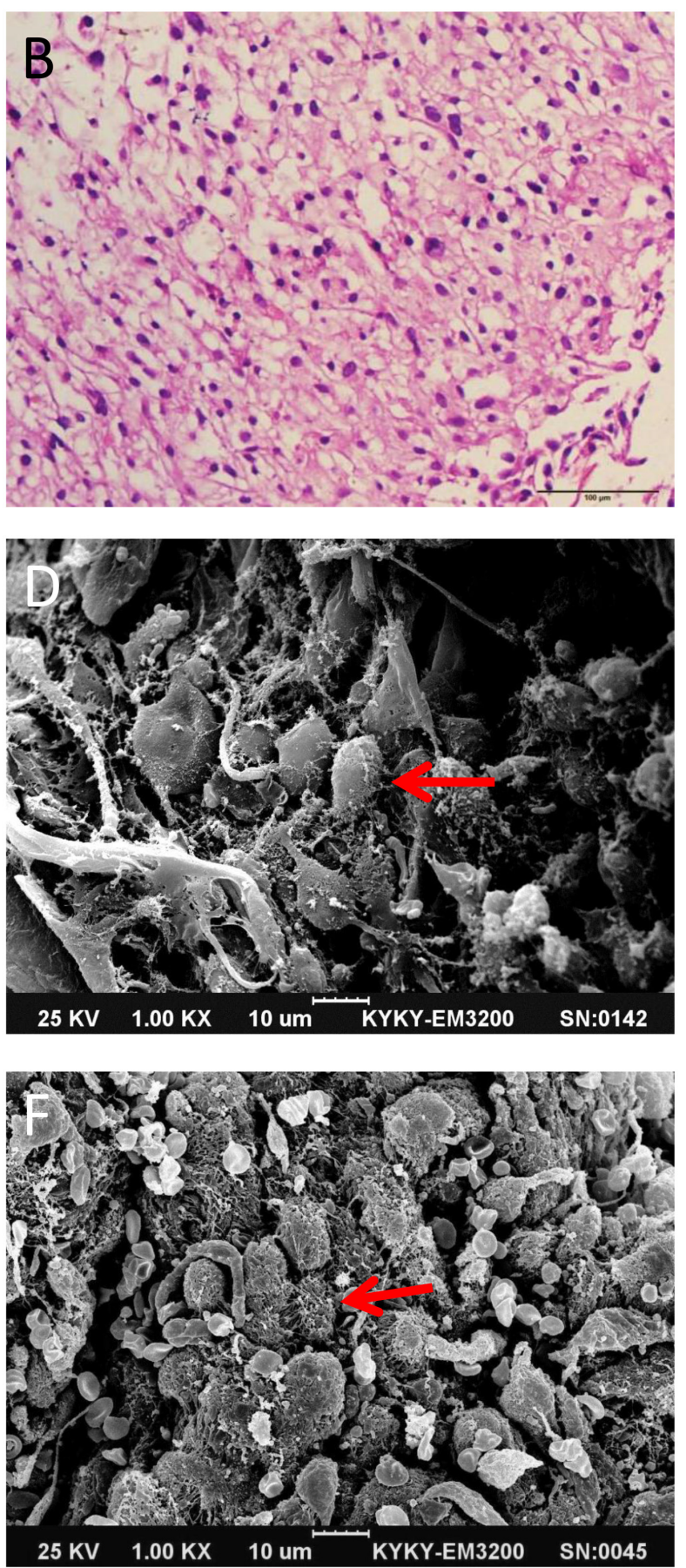

Figure 1: Comparison of glioma cell morphology by H\&E staining and SEM. Primary glioma cells in 2D and 3D culture with H\&E staining A and B. Scale bar $=100 \mu \mathrm{m}$. U87 cells in 2D and 3D culture in SEM image C and D. Scale bars $=100 \mu \mathrm{m}$ and 10 $\mu \mathrm{m}$. Primary glioma cells in 3D scaffolds and human glioma tissue imaged by SEM E and F. Scale bars $=100 \mu \mathrm{m}$ and $10 \mu \mathrm{m}$. Red arrow indicates glioma cells. 

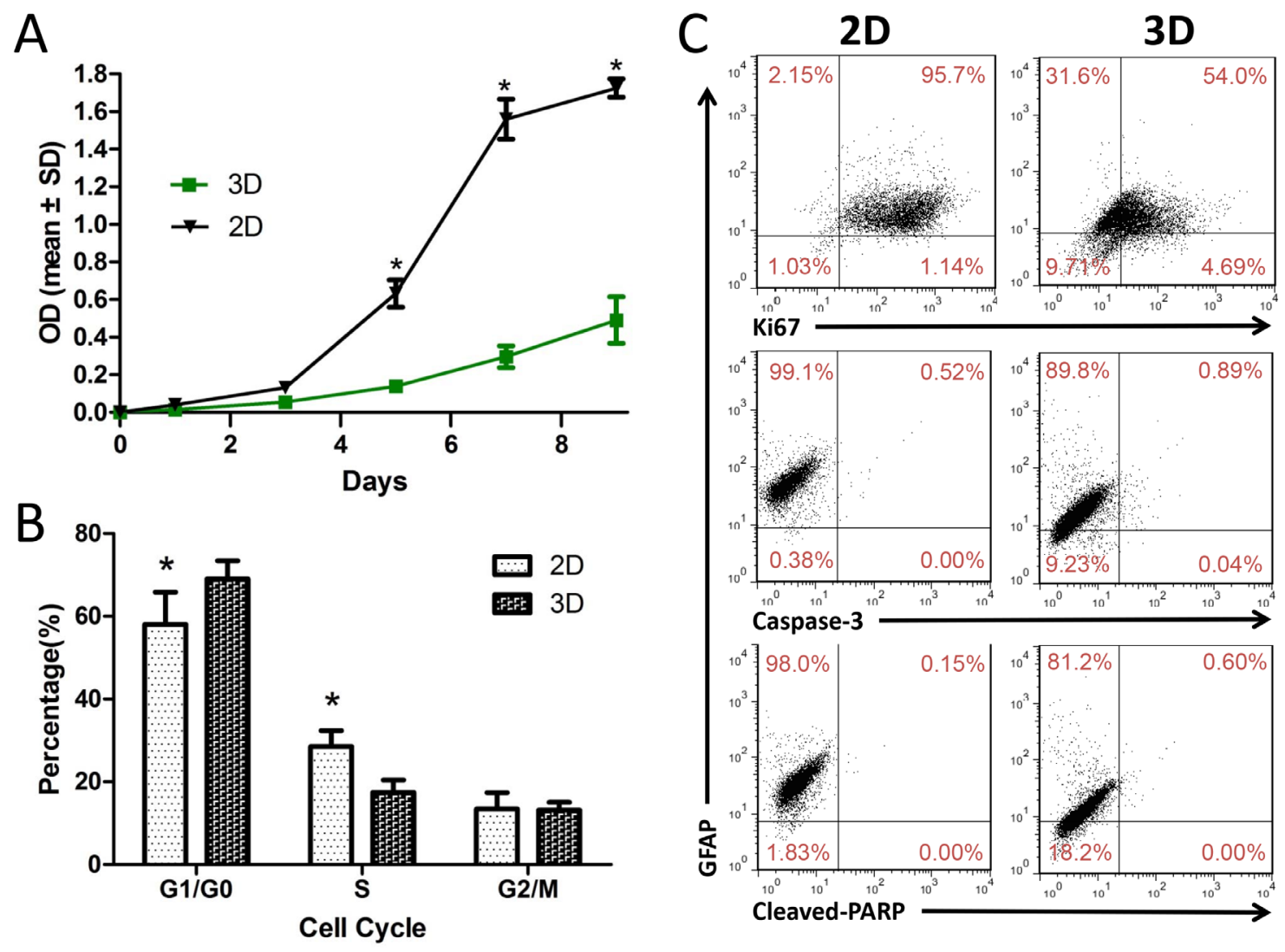

Figure 2: U87 cell proliferation and dedifferentiation in 3D collagen scaffolds. U87 cell proliferation in 2D and 3D culture assessed at different time points A. 3D culture induces accumulation of cells in G0/G1 phase with concomitant reduction of cells in S phase B. Levels of Ki67, caspase-3, cleaved-PARP and GFAP in U87 cells in 2D and 3D culture as measured using flow cytometry C. Results are shown as the means $\pm \mathrm{SD}$. $* P<0.05$.
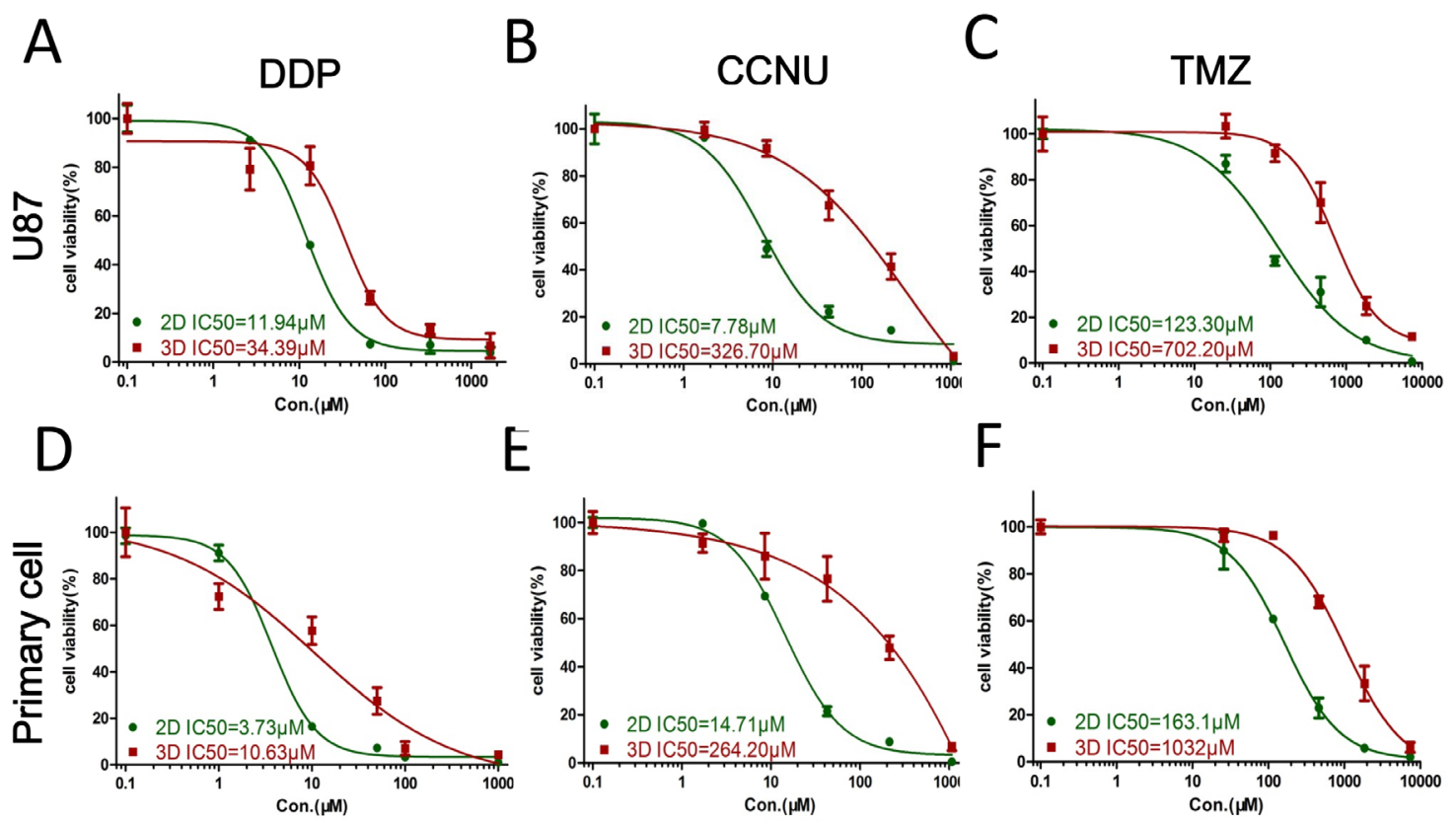

$\mathrm{E}$
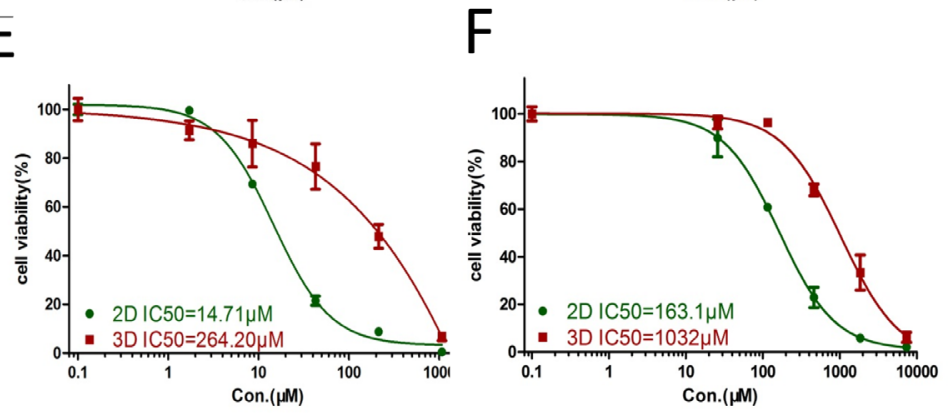

Figure 3: Glioma cell responses to chemotherapeutics. U87 and primary glioma cell viabilities in $2 \mathrm{D}$ and 3D culture after exposure to DDP A and D. CCNU B and E. and TMZ C and F. Data represent the mean percentage viability (2D and 3D; left axis) \pm SD normalized against untreated control cells. 
IF staining was observed in $3 \mathrm{D}$, but not $2 \mathrm{D}$, culture slides (Figure 5A). The mean ratio of $\mathrm{CD} 133^{+}$cells to total cells was $1.39 \pm 1.96 \%$ in $2 \mathrm{D}$ cultures vs. $7.48 \pm 1.13 \%$ in $3 \mathrm{D}$ cultures (Figure 5B). Flow cytometry showed that $0.29 \%$ and $4.34 \%$ of GSCs were $\mathrm{CD} 133^{+}$in $2 \mathrm{D}$ and $3 \mathrm{D}$ cultures, respectively (Figure 5C). The proportion of GSC-like U87 cells grown in collagen scaffolds was 15 -fold higher than that in monolayer culture. The stemness factors, Nanog and Sox2, were upregulated by $4.77 \pm 0.51$-fold and $15.25 \pm 3.11$-fold, respectively, in 3D cultured U87 cells (Figure 5D-5E). We also found that 3D culture increased U87 cell colony and spheroid formation (Figure $5 \mathrm{~F}-5 \mathrm{G}$ ) by approximately two-fold compared with cells in 2D culture. Enhanced stemness-associated properties were also observed in primary glioma cells in 3D culture (Supplementary Figure S3). These data indicate that 3D collagen scaffolds promote glioma cell stemness, activation of GSCs-associated factors and self-renewal.

\section{Chemotherapeutic drug treatments}

DDP, CCNU and TMZ are prototype chemotherapeutic agents verified in previous clinical trials. U87 and primary glioma cell inhibition efficacy was investigated according to individual drug peak plasma concentrations (PPCs) as measured in human blood. In $2 \mathrm{D}$ culture, the mean inhibition rates of DDP, CCNU and TMZ were $80.85 \pm 1.17 \%, 72.27 \pm 4.30 \%$ and $72.19 \pm$ $2.83 \%$ in U87 cells, and $52.03 \pm 1.12 \%, 93.89 \pm 2.48 \%$ and $76.95 \pm 2.08 \%$ in primary glioma cells. In $3 \mathrm{D}$ culture, the rates were $13.53 \pm 11.77 \%, 6.78 \pm 5.73 \%$ and $27.60 \pm$ $11.11 \%$ in U87 cells, and $28.18 \pm 4.26 \%, 28.65 \pm 9.13 \%$ and $45.04 \pm 5.51 \%$ in primary glioma cells (Figure 6). The chemosensitivity of glioma cells in $3 \mathrm{D}$ culture more closely resembled clinical objective response rates for all drugs as compared to $2 \mathrm{D}$ cultures.

\section{DISCUSSION}

Due in part to the complexity of the tumor microenvironment, traditional 2D culture of tumor cells often does not accurately mimic the in vivo properties. Previous studies in 3D glioma culture systems commonly used gels, such as matrigel [19] or hydrogel [20]. Although these systems exhibit good biocompatibility, cell viability tests, such as MTT, CCK8 or Alamar Blue assay, are difficult to perform in gels. Thus, tumor studies in gels are usually focused on invasion, motility or specific signaling

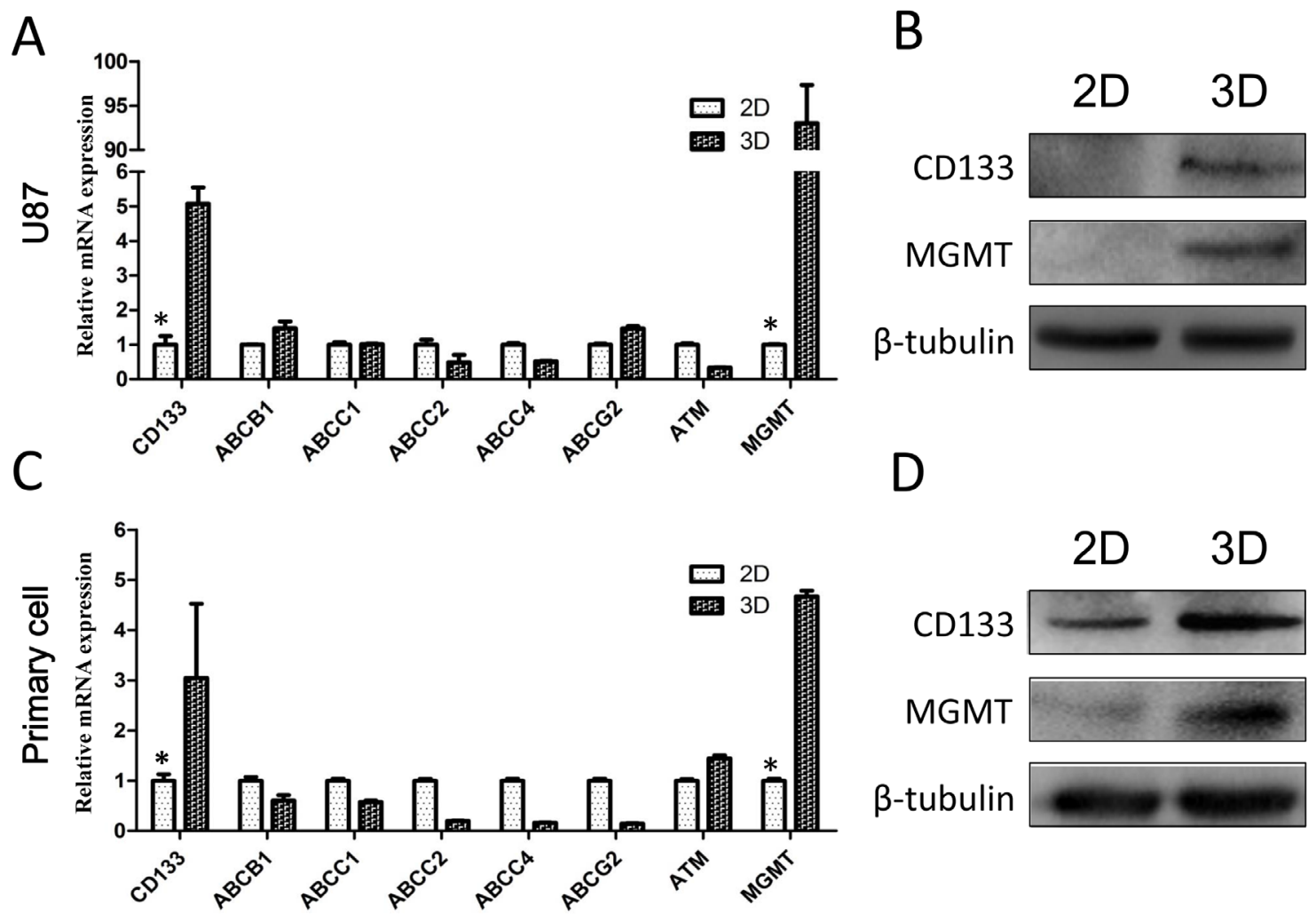

Figure 4: Chemotherapy resistance mechanisms shown by 3D-cultured glioma cells. Levels of drug resistance-related genes were examined by qRT-PCR in U87 A. and primary glioma cells C. Expression data was normalized against GAPDH. MGMT and CD133 expression in U87 B. and primary D. cells via Western blotting. ${ }^{*} P<0.05$. 
pathway activation. Compared with gel, the $3 \mathrm{D}$ scaffold system is suitable for cancer screening of therapeutics. A previous glioma drug study was performed using a chitosan-hyaluronic acid (HA) scaffold [15], which induced weak drug resistance corresponding to increased ABCG2 expression. However, MGMT overexpression is a main reason for glioma drug resistance in clinical cases [21], and collagen, not hyaluronic acid, is the main ECM component in glioma tissues. Use of appropriate ECM components is therefore critically important in monitoring tumor cell responses to exogenous cues such as growth factor activation or chemotherapy. In this study, we developed a porous 3D scaffold mainly containing collagens I and IV, the primary ECM components in

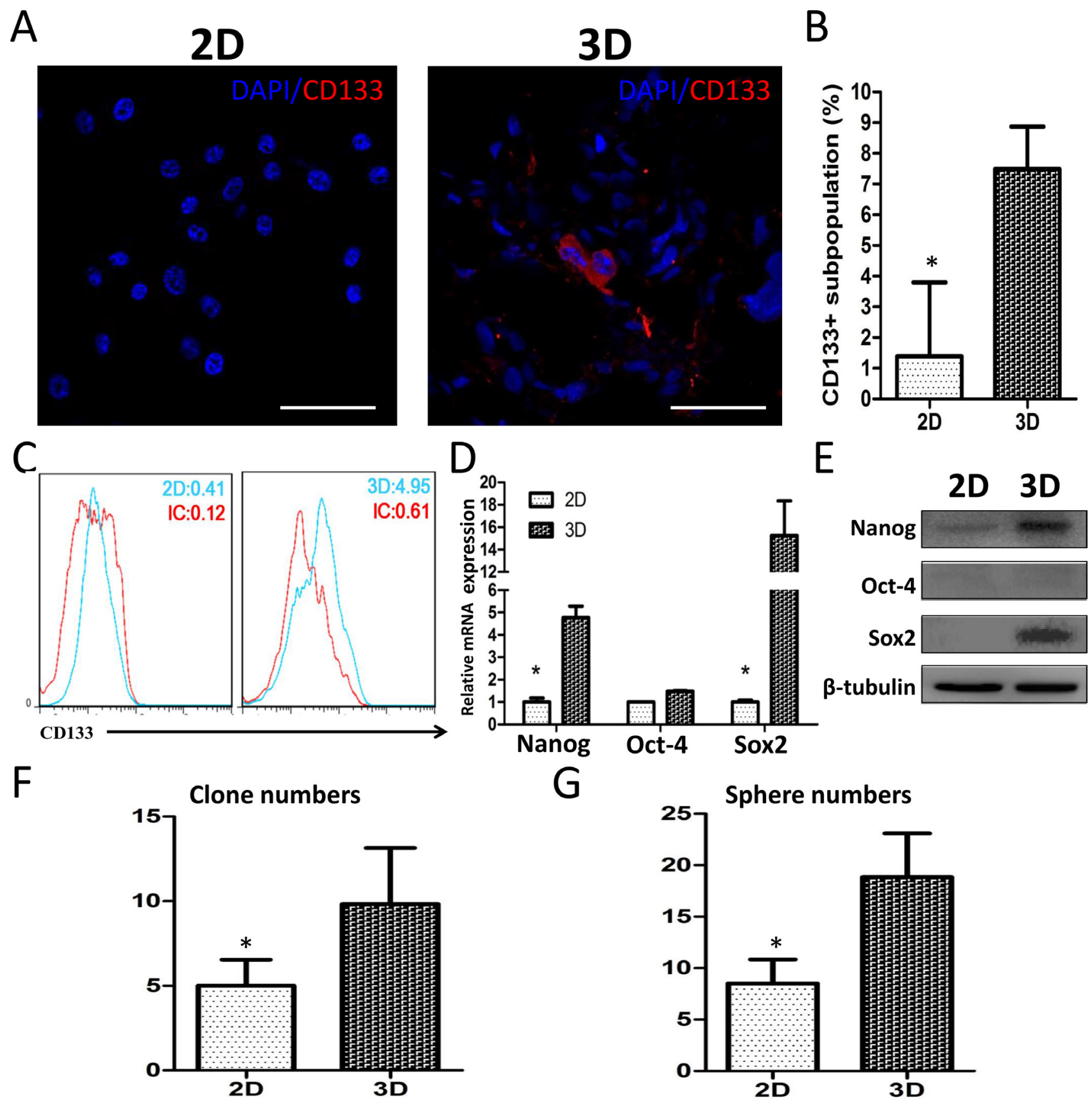

Figure 5: U87 cell stemness in 3D culture. CD133 expression shown by confocal microscopy A and B. and flow cytometry C. Scale bar $=100 \mu \mathrm{m}$. Relative Nanog, Oct4 and Sox 2 mRNA D. and protein E. levels in cultured cells as measured by qRT-PCR and Western blotting. qRT-PCR data was normalized against GAPDH. Colony and sphere formation by U87 cells in 3D culture F and G. Data represent the means \pm SD. $* P<0.05$. 
glioma [22]. These scaffolds have several advantages, including high porosity, a large surface area-to-volume ratio for cellular attachment, tunable pore diameter, low cost and high reproducibility of culture condition. Using this scaffold, we created a 3D glioma culture model with features different from those of conventional in vitro 2D culture systems. Increased chemotherapy resistance was observed in 3D culture tumor cells as a result of increased stemness and upregulation of cell self-rehabilitation protein, MGMT. To our knowledge, this is the first observation that changing culture dimensions and ECM components induces MGMT overexpression by glioma cells.

The mechanism for enhancement of glioma cell stemness in 3D culture is not yet clear. GSC-enriched microenvironments are complex, but frequently include a variety of cytokine changes, hypoxia and poor local nutritional conditions [23]. 3D culture may provide regions of hypoxia and improve cell-cell communications [24, 25]. Hypoxia can reduce cell sensitivity to growth signals and cause the accumulation of GSCs in G0 phase of the cell cycle $[26,27]$, especially in 3D organoid systems [28]. This may explain increased number of quiescent cells in 3D scaffold cultures.

Drug resistance in glioma is associated with drug efflux, metabolism, cancer stem cells, DNA damage repair, and miRNA activity [29, 30]. Previous studies have described the relationship between cancer cell stemness and tumor chemosensitivity. For example, TMZ may fail to inhibit GSC self-renewal [31] via activation of the EGFR and SHH pathways [32] or various ATP binding cassette transporters [33]. Additionally, GSC quiescence and long life span also enhance drug resistance $[34,35]$.
Consistent with clinical results, we found that MGMT was upregulated in glioma cells in 3D collagen scaffold cultures. High MGMT activity in glioma promotes resistance to alkylating agent chemotherapeutics [36-38], as shown by increased resistance of our 3D-cultured glioma cells to CCNU and TMZ. Notably, U87 cells in 2D culture are MGMT-negative, but MGMT was upregulated in cells grown on the 3D scaffolds. Sox2 activation was also found in glioma cells in 3D culture, and MGMT activation may be induced by Sox 2 [39]. Therefore, 3D collagen scaffold culture provides glioma cells with a microenvironment conducive to drug resistance, at least in part through GSC enrichment and enhanced DNA damage repair.

The reported clinical response rates of glioma patient to chemotherapeutics DDP, CCNU and TMZ were $10 \%$ [40], 12 21\% [41, 42] and 7 40\% [43-45], respectively. Our data suggest that treatment of glioma cells with these drugs in 3D culture more closely simulated clinical response rates as compared to cells in $2 \mathrm{D}$ culture.

In conclusion, we developed an in vitro 3D glioma cell culture system using collagen scaffolds that provide cell attachment structures. Glioma cells grown in these 3D cultures exhibited morphological and biochemical differences compared with cells grown in conventional 2D cultures, including enhanced chemotherapy resistance, GSC enrichment and MGMT overexpression. Importantly, tumor cells in 3D culture showed similar chemotherapy resistance patterns as those observed in glioma patients. Our results thus suggest that $3 \mathrm{D}$ collagen scaffolds are promising in vitro research platforms for screening new anti-glioma therapeutics.
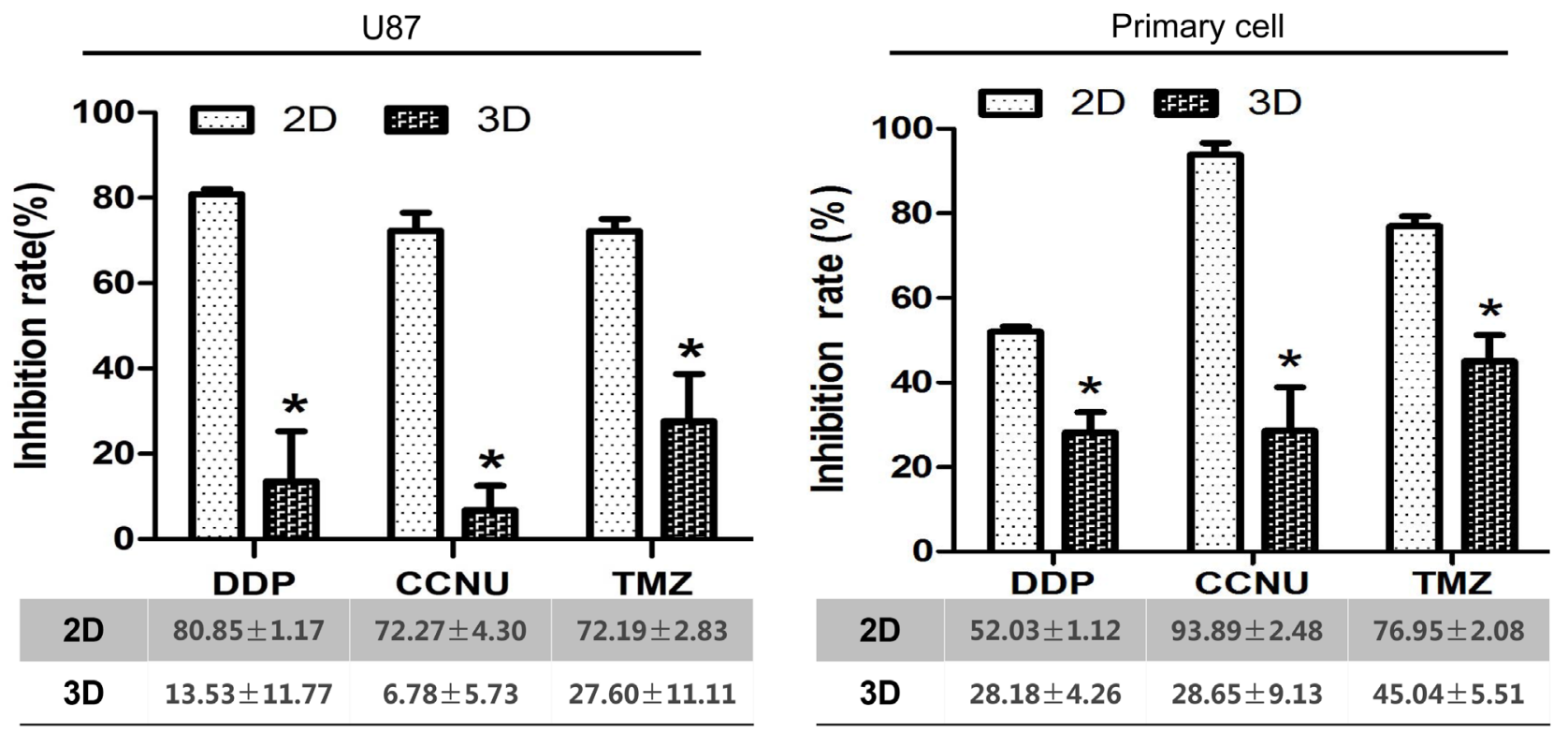

Figure 6: Inhibition of growth of U87 and primary glioma cells by DDP, CCNU and TMZ in 2D vs. 3D culture. * $P<0.05$. 


\section{MATERIALS AND METHODS}

\section{Preparation of 3D collagen scaffolds}

Collagen scaffolds were fabricated from collagen membranes, made from bovine collagen of spongy bone, obtained from the Institute of Combined Injury of the Third Military Medical University. Briefly, collagen membranes were immersed in $0.5 \mathrm{M}$ acetic acid for $8 \mathrm{~h}$ at $4^{\circ} \mathrm{C}$, mixed in a blender for $15 \mathrm{~min}$ and neutralized by $4 \mathrm{M} \mathrm{NaOH}$. The homogeneous solution was dialyzed in deionized water for $5 \mathrm{~d}$ and lyophilized. We produced collagen scaffolds with $50 \mu \mathrm{m}$ average pore sizes. Scaffolds were cut into $1 \times 5 \times 5 \mathrm{~mm}$ pellets and crosslinked by $1 \mathrm{mg} / \mathrm{ml}$ 1-ethyl-3-(3-dimethyl aminopropyl) carbodiimide and $0.6 \mathrm{mg} / \mathrm{ml} \mathrm{N}$-hydroxysuccinimide. After crosslinking, pellets were lyophilized again, sterilized by $60 \mathrm{Co}$ and stored at ambient temperature.

\section{Primary glioma samples and cells}

Tissue collection and analysis were approved by the Ethics Committee of Southwest Hospital, Third Military Medical University, and written informed consent was obtained from the participants. Human glioma tissues used for primary cell culture were obtained from one GBM patient who underwent neurosurgical operation in December 2009. The diagnosis was verified by pathological analysis and classified according to the WHO classification standard. Primary glioma cell isolation and culture was performed in our lab as described previously $[46,47]$. The GBM cell line, U87, was purchased from the American Type Culture Collection.

\section{D and 3D glioma cell culture}

For 2D culture, cells were seeded onto $60 \mathrm{~mm}$ dishes and maintained in DMEM supplemented with $10 \%$ FBS and $1 \%$ penicillin-streptomycin at $37^{\circ} \mathrm{C}$ and $5 \% \mathrm{CO}_{2}$. For 3D scaffold culture, following immersion in $10 \%$ FBS-supplemented medium for $12 \mathrm{~h}$ at $37^{\circ} \mathrm{C}$, collagen scaffolds were loaded with cell suspensions (200,00 cells in $20 \mu \mathrm{L}$ medium per scaffold) and maintained at $37^{\circ} \mathrm{C}$ for $4 \mathrm{~h}$. Then, scaffolds with seeded cells were transferred to 6 -well cell culture plates containing $3 \mathrm{ml}$ medium; medium was changed every 2 days.

\section{Cell morphology analysis}

Cell morphology was observed via Hematoxylin and eosin (H\&E) staining and Scanning Electron Microscopy (SEM). Specimens (7 days) were fixed in 4\% paraformaldehyde, embedded in paraffin, cut into for 5 $\mu \mathrm{m}$ sections and H\&E stained. For SEM analysis, scaffold or glioma samples were fixed in $2.5 \%$ glutaraldehyde overnight, dehydrated in an ethanol gradient (70-100\%), air-dried overnight, sputter-coated with gold and imaged (KYKY EM-3200). Glioma samples were quickly frozen in liquid nitrogen after surgical resection until use and fragmented immediately after removal from liquid nitrogen. A specimen with a diameter of about $1.5 \mathrm{~mm}$ was chosen for fixation.

\section{Cell proliferation assay}

Cell viabilities in both 2D monolayers and 3D scaffolds were measured indirectly by the Cell Counting Kit-8 (CCK8) (Beyotime Technologies, C0038). Briefly, the original medium was replaced with $100 \mu \mathrm{l}$ medium containing $10 \%$ CCK -8 . The reaction was incubated at $37^{\circ} \mathrm{C}$ for $1.5 \mathrm{~h}$ and the solution was moved to a new $96-$ well plate for spectrophotometric measurement at 450 $\mathrm{nm}$ using a microplate reader (Varioskan Flash, Thermo Electron Corporation). Four parallel replicates of each sample were analyzed daily. DMEM containing 10\% CCK-8 was used as a control.

\section{Flow cytometry}

For cell cycle analysis, glioma cells (5 days) were washed twice with PBS and fixed in $75 \%$ cold ethanol at $4^{\circ} \mathrm{C}$ overnight. Fixed cells were washed with cooled PBS and stained using the cell cycle assay kit (Bestbio, BB-4104). The experiment was repeated three times. For proliferation and apoptosis analysis, Caspase-3, Ki67 and cleaved poly (ADP-ribose) polymerase (PARP) were labeled with conjugated monoclonal antibodies (BD Biosciences) after U87 cell permeabilization. For CD133 expression analysis, cells were blocked by FcR blocking reagent (Miltenyi, 130-059-901) and then incubated with CD133/1-APC (Miltenyi, 130-090-826) at $4^{\circ} \mathrm{C}$ for 30 $\mathrm{min}$. Cells were washed twice and resuspended with cold PBS. 7-AAD (BD Biosciences, 51-68981E) was added to cell suspensions to identify dead cells. Mouse IgG1-APC (Miltenyi, 130-092-214) was used as the isotype control. All analyses were performed on a FACS Calibur analyzer (BD Biosciences) using FlowJo software (Tree Star).

\section{Immunofluorescent staining}

Samples were fixed overnight in $4 \%$ paraformaldehyde, cut into $15 \mu \mathrm{m}$ sections and affixed to slides. Slides were blocked with $10 \%$ BSA for $1 \mathrm{~h}$, incubated with anti-human CD133 (Boster, BA3992) overnight at $4^{\circ} \mathrm{C}$, then washed three times in PBS and incubated with Alexa Fluor 647 secondary antibodies (Invitrogen, A21244) in the dark for $1 \mathrm{~h}$ at room temperature. Finally, slides were stained with $0.1 \%$ 4', 6-diamidino-2-phenylindole (DAPI) to visualize cell nuclei, washed twice with PBS and examined via confocal microscopy (Leica LSM780). Image analysis was performed using ZEN software. Four random microscopy 
fields were selected for quantitative analysis, and the ratio of $\mathrm{CD}_{133^{+}}$cells to total cells in each field was determined by manual counting.

\section{Chemosensitivity assay}

Dose-responses for chemotherapeutics were evaluated in $2 \mathrm{D}$ and $3 \mathrm{D}$ cultures. Glioma cells $\left(5 \times 10^{3}\right.$ cells/well) were seeded on either monolayer or scaffold in a 96-well plate and allowed to grow for $24 \mathrm{~h}$ before treatment. Then, culture medium was replaced with fresh medium containing various concentrations of the anticancer drugs, temozolomide (TMZ) (Meilun, 8562293-1), lomustine (CCNU) (Meilun, 13010-47-4) and cisplatin (DDP) (Sigma, 479306), for IC50 analysis. To better compare with clinical outcomes, anti-glioma inhibition rates were investigated according to drug PPCs of human blood in 2D and 3D culture. PPCs of the three tested drugs were TMZ: $258.0 \mu \mathrm{M}, \mathrm{CCNU}: 14.0 \mu \mathrm{M}$ and DDP: $12.8 \mu \mathrm{M}$ [48-50]. After $24 \mathrm{~h}$, drug-containing medium was replaced with fresh medium and cells were incubated for $48 \mathrm{~h}$. After treatment, chemosensitivity was determined using the CCK8 assay. Percent antiglioma inhibition rates were calculated as the average cell viability in each drug group as compared to the average viability in the untreated group. All experiments were performed in triplicate.

\section{RNA isolation and quantitative RT-PCR}

Total mRNA was isolated from tumor cells (5 day) using TRIzol ${ }^{\mathrm{TM}}$ Reagent (Invitrogen), following the manufacturer's instructions. cDNA was synthesized using the PrimeScript ${ }^{\circledR}$ First Strand cDNA Synthesis Kit (TaKaRa, D6110A). QRT-PCR was performed via the CFX96 Real-Time PCR Detection System (BioRAD, 185-5195) with the SYBR ${ }^{\circledR}$ PrimeScript ${ }^{\mathrm{TM}}$ RTPCR Kit (TaKaRa, DDR083A). Transcript levels were normalized to GAPDH.

\section{Western blotting}

On day 5, cells cultured in $2 \mathrm{D}$ and $3 \mathrm{D}$ systems were washed twice in PBS and lysed using the M-PER ${ }^{\circledR}$ Mammalian Protein Extraction Reagent (Thermo, 75801) supplemented with proteinase inhibitor cocktail (Roche, 04693116001) for $30 \mathrm{~min}$ on ice. Whole-cell lysates were harvested from the supernatant by centrifugation at $12,000 \mathrm{~g}$ for $15 \mathrm{~min}$. Lysates were electrophoresed in SDS-polyacrylamide gels (Beyotime Technologies, P0012A) and transferred to PVDF membranes (Millipore, IPVH00010). Primary antibodies used in this study included: anti-CD133 (Millipore, W6B3C1), anti-MGMT (Cell Signaling, 2739S), anti-Sox2 (Cell Signaling, 3579P), anti-Nanog (Cell Signaling, 4903), anti-Oct4 (Cell Signaling, 2750), anti-GAPDH (Bioworld, AP0063) and anti- $\beta$-tubulin (Cell Signaling, 2146S). A secondary HRP- linked goat anti-rabbit IgG antibody (Thermo, 31210) or goat anti-mouse IgG antibody (Thermo, 31431) was used as appropriate. Results were visualized using SuperSignal West Dura chemiluminescent substrate (Thermo Fisher Scientific).

\section{Colony and sphere formation assays}

For colony formation assays, U87 cells from different culture models were plated (200 cells/well) in complete medium in a 24-well plate, and were allowed to form colonies for 12 days. Colonies were fixed with acetic acid and methanol (1:3) for $15 \mathrm{~min}$ and stained with $0.5 \%$ crystal violet for $30 \mathrm{~min}$. Colonies containing more than 50 cells were counted manually. For sphere formation assays, cells were seeded in serum-free neural stem cell medium (DMEM/F12 medium containing $20 \mathrm{ng} / \mathrm{ml}$ recombinant human epidermal growth factor, $20 \mathrm{ng} / \mathrm{ml}$ basic fibroblast growth factor and 2\% B27) (200 cells/well) into a 96-well plate. Spheroids were counted manually by inverted phase contrast microscopy after 10 days.

\section{CONFLICTS OF INTEREST}

The authors declare no conflicts of interest.

\section{GRANT SUPPORT}

This project was supported by grants from the National Natural Science Foundation of China (No. 81230062, No. 81372684 and No. 61327902).

\section{REFERENCES}

1. Assi H, Candolfi M, Baker G, Mineharu Y, Lowenstein PR, Castro MG. Gene therapy for brain tumors: basic developments and clinical implementation. Neuroscience letters. 2012; 527:71-77.

2. Van Meir EG, Hadjipanayis CG, Norden AD, Shu HK, Wen PY, Olson JJ. Exciting New Advances in Neuro-Oncology The Avenue to a Cure for Malignant Glioma. Ca-Cancer J Clin. 2010; 60:166-193.

3. Shoemaker RH. The NCI60 human tumour cell line anticancer drug screen. Nature Reviews Cancer. 2006; 6:813-823.

4. Fallica B, Makin G, Zaman MH. Bioengineering approaches to study multidrug resistance in tumor cells. Integrative biology: quantitative biosciences from nano to macro. 2011; 3:529-539.

5. Birgersdotter A, Sandberg R, Ernberg I. Gene expression perturbation in vitro - A growing case for three-dimensional (3D) culture systems. Seminars in Cancer Biology. 2005; 15:405-412.

6. Abbott A. Cell culture: Biology's new dimension. Nature. $2003 ; 424: 870-872$. 
7. Cheng L, Bao SD, Rich JN. Potential therapeutic implications of cancer stem cells in glioblastoma. Biochem Pharmacol. 2010; 80:654-665.

8. Dhiman HK, Ray AR, Panda AK. Characterization and evaluation of chitosan matrix for in vitro growth of MCF-7 breast cancer cell lines. Biomaterials. 2004; 25:5147-5154.

9. Duan JJ, Qiu W, Xu SL, Wang B, Ye XZ, Ping YF, Zhang $\mathrm{X}$, Bian XW, Yu SC. Strategies for Isolating and Enriching Cancer Stem Cells: Well Begun Is Half Done. Stem Cells Dev. 2013; 22:2221-2239.

10. Martin KJ, Patrick DR, Bissell MJ, Fournier MV. Prognostic Breast Cancer Signature Identified from 3D Culture Model Accurately Predicts Clinical Outcome across Independent Datasets. Plos One. 2008; 3.

11. Wang X, Sun L, Maffini MV, Soto A, Sonnenschein C, Kaplan DL. A complex 3D human tissue culture system based on mammary stromal cells and silk scaffolds for modeling breast morphogenesis and function. Biomaterials. 2010; 31:3920-3929.

12. Chen L, Xiao Z, Meng Y, Zhao Y, Han J, Su G, Chen B, Dai J. The enhancement of cancer stem cell properties of MCF-7 cells in 3D collagen scaffolds for modeling of cancer and anti-cancer drugs. Biomaterials. 2012; 33:1437-1444.

13. Fong ELS, Lamhamedi-Cherradi SE, Burdett E, Ramamoorthy V, Lazar AJ, Kasper FK, Farach-Carson MC, Vishwamitra D, Demicco EG, Menegaz BA, Amin HM, Mikos AG, Ludwig JA. Modeling Ewing sarcoma tumors in vitro with 3D scaffolds. P Natl Acad Sci USA. 2013; 110:6500-6505.

14. Bonneh-Barkay D, Wiley CA. Brain extracellular matrix in neurodegeneration. Brain pathology. 2009; 19:573-585.

15. Florczyk SJ, Wang K, Jana S, Wood DL, Sytsma SK, Sham JG, Kievit FM, Zhang MQ. Porous chitosan-hyaluronic acid scaffolds as a mimic of glioblastoma microenvironment ECM. Biomaterials. 2013; 34:10143-10150.

16. Huijbers IJ, Iravani M, Popov S, Robertson D, Al-Sarraj S, Jones C, Isacke CM. A role for fibrillar collagen deposition and the collagen internalization receptor endo180 in glioma invasion. Plos One. 2010; 5:e9808.

17. Leitinger B. Transmembrane collagen receptors. Annual review of cell and developmental biology. 2011; 27:265-290.

18. Qiu ZK, Shen D, Chen YS, Yang QY, Guo CC, Feng BH, Chen ZP. Enhanced MGMT expression contributes to temozolomide resistance in glioma stem-like cells. Chin J Cancer. 2014; 33:115-122.

19. Rao SS, Bentil S, DeJesus J, Larison J, Hissong A, Dupaix $\mathrm{R}$, Sarkar A, Winter JO. Inherent interfacial mechanical gradients in 3D hydrogels influence tumor cell behaviors. Plos One. 2012; 7:e35852.

20. Ananthanarayanan B, Kim Y, Kumar S. Elucidating the mechanobiology of malignant brain tumors using a brain matrix-mimetic hyaluronic acid hydrogel platform. Biomaterials. 2011; 32:7913-7923.
21. Hegi ME, Diserens AC, Gorlia T, Hamou MF, de Tribolet N, Weller M, Kros JM, Hainfellner JA, Mason W, Mariani L, Bromberg JE, Hau P, Mirimanoff RO, Cairncross JG, Janzer RC, Stupp R. MGMT gene silencing and benefit from temozolomide in glioblastoma. The New England journal of medicine. 2005; 352:997-1003.

22. Payne LS, Huang PH. The pathobiology of collagens in glioma. Molecular cancer research: MCR. 2013; 11:1129-1140.

23. Bexell D, Svensson A, Bengzon J. Stem cell-based therapy for malignant glioma. Cancer Treat Rev. 2013; 39:358-365.

24. Minchinton AI, Tannock IF. Drug penetration in solid tumours. Nature Reviews Cancer. 2006; 6:583-592.

25. Ong SM, Zhao ZQ, Arooz T, Zhao DQ, Zhang SF, Du TH, Wasser M, van Noort D, Yu H. Engineering a scaffoldfree 3D tumor model for in vitro drug penetration studies. Biomaterials. 2010; 31:1180-1190.

26. Ying M, Wang S, Sang Y, Sun P, Lal B, Goodwin CR, Guerrero-Cazares H, Quinones-Hinojosa A, Laterra J, Xia S. Regulation of glioblastoma stem cells by retinoic acid: role for Notch pathway inhibition. Oncogene. 2011; 30:3454-3467.

27. Wurdak H, Zhu ST, Romero A, Lorger M, Watson J, Chiang CY, Zhang J, Natu VS, Lairson LL, Walker JR, Trussell CM, Harsh GR, Vogels H, Felding-Habermann B, Orth AP, Miraglia LJ, et al. An RNAi Screen Identifies TRRAP as a Regulator of Brain Tumor-Initiating Cell Differentiation. Cell Stem Cell. 2010; 6:37-47.

28. Hubert CG, Rivera M, Spangler LC, Wu Q, Mack SC, Prager BC, Couce M, McLendon RE, Sloan AE, Rich JN. A three-dimensional organoid culture system derived from human glioblastomas recapitulates the hypoxic gradients and cancer stem cell heterogeneity of tumors found in vivo. Cancer Res. 2016.

29. Haar CP, Hebbar P, Wallace GC, Das A, Vandergrift WA, Smith JA, Giglio P, Patel SJ, Ray SK, Banik NL. Drug Resistance in Glioblastoma: A Mini Review. Neurochemical Research. 2012; 37:1192-1200.

30. Patil SA, Hosni-Ahmed A, Jones TS, Patil R, Pfeffer LM, Miller DD. Novel approaches to glioma drug design and drug screening. Expert Opin Drug Dis. 2013; 8:1135-1151.

31. Chua C, Zaiden N, Chong KH, See SJ, Wong MC, Ang BT, Tang C. Characterization of a side population of astrocytoma cells in response to temozolomide. Journal of neurosurgery. 2008; 109:856-866.

32. Yamada R, Nakano I. Glioma Stem Cells: Their Role in Chemoresistance. World Neurosurg. 2012; 77:237-240.

33. Kondo T. Brain cancer stem-like cells. Eur J Cancer. 2006; 42:1237-1242.

34. Qiang L, Yang Y, Ma YJ, Chen FH, Zhang LB, Liu W, Qi Q, Lu N, Tao L, Wang XT, You QD, Guo QL. Isolation and characterization of cancer stem like cells in human glioblastoma cell lines. Cancer Lett. 2009; 279:13-21. 
35. Yu H, Zhang CM, Wu YS. Research progress in cancer stem cells and their drug resistance. Chin J Cancer. 2010; 29:261-264.

36. Hegi ME, Diserens A, Gorlia T, Hamou M, de Tribolet N, Weller M, Kros JM, Hainfellner JA, Mason W, Mariani L, Bromberg JEC, Hau P, Mirimanoff RO, Cairncross JG, Janzer RC, Stupp R. MGMT gene silencing and benefit from temozolomide in glioblastoma. New Engl J Med. 2005; 352:997-1003.

37. Jaeckle K, Ballman K, O’Fallon J, Scheithauer B, Giannini C, Moynihan T, Buckner J. Response to pre-radiation chemotherapy as a predictor of survival in patients with newly diagnosed malignant astrocytoma: A north central cancer treatment group (NCCTG) study. Neuro-Oncology. 2004; 6:376-376.

38. Belanich M, Pastor M, Randall T, Guerra D, Kibitel J, Alas L, Li B, Citron M, Wasserman P, White A, Eyre H, Jaeckle K, Schulman S, Rector D, Prados M, Coons S, et al. Retrospective study of the correlation between the DNA repair protein alkyltransferase and survival of brain tumor patients treated with carmustine. Cancer Res. 1996; 56:783-788.

39. Florio T, Barbieri F. The status of the art of human malignant glioma management: the promising role of targeting tumor-initiating cells. Drug Discov Today. 2012; 17:1103-1110.

40. Ashby LS, Shapiro WR. Intra-arterial cisplatin plus oral etoposide for the treatment of recurrent malignant glioma: a phase II study. Journal of neuro-oncology. 2001; 51:67-86.

41. Arcicasa M, Roncadin M, Bidoli E, Dedkov A, Gigante M, Trovo MG. Reirradiation and lomustine in patients with relapsed high-grade gliomas. International journal of radiation oncology, biology, physics. 1999; 43:789-793.

42. Walbert T, Gilbert MR, Groves MD, Puduvalli VK, Yung WKA, Conrad CA, Bobustuc GC, Colman H, Hsu SH, Bekele BN, Qiao W, Levin VA. Combination of 6-thioguanine, capecitabine, and celecoxib with temozolomide or lomustine for recurrent high-grade glioma. Journal of neuro-oncology. 2011; 102:273-280.

43. Chan DT, Poon WS, Chan YL, Ng HK. Temozolomide in the treatment of recurrent malignant glioma in Chinese patients. Hong Kong medical journal. 2005; 11:452-456.

44. van den Bent MJ, Hegi ME, Stupp R. Recent developments in the use of chemotherapy in brain tumours. Eur J Cancer. 2006; 42:582-588.

45. Oshiro S, Tsugu H, Komatsu F, Ohmura T, Ohta M, Sakamoto S, Fukushima T, Inoue T. Efficacy of Temozolomide Treatment in Patients with High-grade Glioma. Anticancer Res. 2009; 29:911-917.

46. Yi L, Zhou ZH, Ping YF, Chen JH, Yao XH, Feng H, Lu JY, Wang JM, Bian XW. Isolation and characterization of stem cell-like precursor cells from primary human anaplastic oligoastrocytoma. Modern pathology. 2007; 20:1061-1068.

47. Wang Z, Wang B, Shi Y, Xu C, Xiao HL, Ma LN, Xu SL, Yang L, Wang QL, Dang WQ, Cui W, Yu SC, Ping YF, Cui YH, Kung HF, Qian C, et al. Oncogenic miR-20a and miR-106a enhance the invasiveness of human glioma stem cells by directly targeting TIMP-2. Oncogene. 2015; 34:1407-1419.

48. Lewandowicz GM HB, Harkness W, Hayward R, Thomas DG, Darling JL. Chemosensitivity in childhood brain tumours in vitro- evidence of differential sensitivity to lomustine (CCNU) and vincristine. Eur J Cancer. 2000; 36:1955-1964.

49. Linz U, Ulus B, Neuloh G, Clusmann H, Oertel M, Nolte K, Weis J, Heussen N, Gilsbach JM. Can in-vitro chemoresponse assays help find new treatment regimens for malignant gliomas? Anti-Cancer Drug. 2014; 25:375-384.

50. Ono A, Kanno H, Hayashi A, Nishimura S, Kyuma Y, Sato H, Ito S, Shimizu N, Chang CC, Gondo G, Yamamoto I, Sasaki T, Tanaka M. Collagen gel matrix assay as an in vitro chemosensitivity test for malignant astrocytic tumors. Int J Clin Oncol. 2007; 12:125-130. 